dilemmas in medicine and relates them to the central theories of moral philosophy. The new edition has extended and updated the references and added a section on recommended reading for those - let us hope an increasing number - who wish to study the subject in greater depth. Although the book contains many examples from different areas of medical practice it is not padded out with over-elaborate descriptions of actual cases. Likewise the discussions of philosophers or theologians, while not superficial, do not contain more detail than would be found helpful by a busy clinician or general practitioner. The last chapter in the book deals with a few current problems. Many are mentioned and four discussed in more detail-abortion, death and dying, control of clinical research and organ transplantation. These are, of course, matters of continuing importance, but in the next edition of his book he might consider adding a lengthier discussion of the radical challenge mounted by Ivan Illich - that Western, science-based medicine does not make for the enhancement of health. There is a tendency in the medical profession to dismiss the radical challenge, but increasing numbers of ordinary people are becoming disenchanted with 'professional' scientific medicine and turning elsewhere. But medical education does not change in its essentials. It has however changed sufficiently to make this book an acceptable text for medical ethics courses.

R S DOWNIE

Professor of Moral Philosophy, Glasgow

University

\section{Respect for Life, a Symposium}

Christian Medical Fellowship, 157 Waterloo Road, London SE1 8XN

47 pages, £1.25, 1984

This brief symposium encapsulates the main attitudes to what the first contributor calls 'a vast increase in medical-moral problems and a crisis of the first magnitude in medical ethics'. The contributor is the late Dr Ian Ramsey, Bishop of Durham, who was an outstanding philosopher and ethicist. It is a paper which he wrote for the Annual Clinical Meeting of the British Medical Association in Cyprus in 1972, and is a classic writing which it is very useful to have reprinted. $\mathrm{He}$ describes the ethical crisis as 'the medical version of the general problem of giving a moral direction to applied science in a society where traditional moral absolutes are being questioned, the general problem of ensuring a humane and not a tyrannical technology, at a time when society lacks a common morality'. He asks what in fact are the prima facie medical concerns if one teases out the pre-suppositions, implicit as well as explicit, in medical papers; and by a carefully built up argument he concludes that they amount to 'a respect for human life of $a$ certain quality in society'. He points out that difficult decisions involving judging one kind of human life to be better than another, from which we might well shrink, cannot be avoided because practical situations with limited resources compel them. In general no simple decisions can be made by one medical man alone, still less solely by politicians or financiers; they require consultative trans-disciplinary groups to illuminate them, and in the course of their work to develop multi-parameter scoring and a multiple criterion. In discussing suffering, and the significance of death, Ramsey introduces Christian considerations, but the general argument does not involve them and is an illustration of the important point that the method of Christian ethics is no different from that of philosophical ethics.

The other three contributions to the symposium are shorter, and they are all concerned with the bearing of increased dependence on medical technology on our understanding of humaneness. $\mathrm{Mr}$ D B Millar, a consultant obstetrician and gynaecologist in Sheffield, shows how fetal worth is already related to gestational age in both medicine and law; and that the details of desirable laws or professional codes cannot be derived directly from Biblical texts. Professor Gareth Jones of Otago, New Zealand (Anatomy) discusses the same area of ethical issues as the Warnock Report. He is cautiously in favour of in vitro fertilisation (IVF) but against research on embryos (unlike Millar who is in favour of it), and therefore against the guidelines for research on IVF and embryo transfer (ET) issued by the Medical Research Council (MRC) in 1982 , as not showing enough respect for human embryos; though he takes issue with the moralist Paul Ramsey as being too restrictive. The most conservative position is that of Professor David Short of Aberdeen (Clinical Medicine), who explains why the Arthur case caused him to change his mind about the management of handicapped neonates. But his three reasons are not very cogent in the light of the previous contributions. (1) Human life should always be preserved provided undue suffering can be avoided. All the dilemmas are hidden in the word 'undue'. Short thinks the kind of decision Ramsey says we cannot avoid making too subjective to make. (2) It is a volte face compared with the Hippocratic tradition. But this is a purely individualistic one as concerning doctor and patient, not society. (3) We must show utmost respect for human life from conception. He and Gareth Jones use the 'wedge argument'; fear of what will happen if an absolute position is not maintained. This is not a satisfactory position. It is true that 'boundary situations' do arise where an absolute position is called for; but most moral decisions are in 'grey areas' where moral wisdom is needed for careful discernment. This is what Ian Ramsey was exploring.

The fact that this symposium is brief should not cause it to be overlooked. It is thoughtful and was well worth putting together.

RONALD PRESTON Professor Emeritus, Faculty of Theology, Manchester University

\section{A Time to Die}

Robert G Twycross, 32 pages, London $60 \mathrm{p}$, Christian Medical Fellowship, 1984

'Today's dying - and their fellow travellers, the bereaved - are today's lepers: unwanted shunned, ignored': writes Robert Twycross in this short booklet, which has the aim of overcoming this approach by society to dying patients. He writes as a Christian and a hospice physician with many years experience of caring for dying patients. He argues that the dying patient and his family should be cared for as 'whole persons' so that the time left can be used for living.

He first describes how in present-day society most people are divorced from death and this may exaggerate the natural fear of death. To care for the dying it is necessary to remain alongside the patient, but this may cause many stresses. These are due to the natural unease of death, the cultural collective fear of dying, especially of cancer, and the ensuing feelings of helplessness. However, he emphasises, using patients' histories, that although facing up to death may be disturbing, it is possible to adjust to the series of losses involved in dying. This may mean the professional coping with both the cries 